\title{
SIDS, illness, and acute medical care
}

R P K Ford, E A Mitchell, A W Stewart, R Scragg, B J Taylor, and other members of the New Zealand Cot Death Study Group $†$

\begin{abstract}
One component of the Back to Sleep campaign to reduce the risk of sudden infant death syndrome (SIDS) is the recommendation that parents seek medical attention if their infant is unwell. The aim of this study was to investigate if SIDS could in part be explained by sick infants not getting appropriate medical care. Data on symptoms of illness and on acute medical contacts made for infants dying from SIDS $(n=390)$ within two weeks of their death were compared with those from a randomly selected group of control infants $(n=1592)$. SIDS cases had more severe illness than controls (odds ratio $(\mathrm{OR})=3.43 ; 95 \%$ confidence interval $(C I)=1.69$ to 5.38$)$, and were more likely to have seen a general practitioner $(\mathrm{OR}=$ $1.37 ; 95 \% \mathrm{CI}=1.09$ to 1.73$)$ or attended hospital $(\mathrm{OR}=3.43,95 \% \mathrm{CI}=1.09$ to 1.73$)$. Only $1.3 \%$ of all SIDS cases had symptoms suggesting severe illness and had not seen a general practitioner. A lack of medical contacts in the two weeks before death does not contribute to the risk of SIDS. (Arch Dis Child 1997;77:54-55)
\end{abstract}

Keywords: SIDS; case-control study; illness; medical contact

Community Paediatrics, Christchurch, New Zealand R P K Ford

University of Auckland, Auckland, New Zealand: Department of Paediatrics E A Mitchell

Department of Biostatistics A W Stewart

Department of Epidemiology R Scragg

Department of Paediatrics, University of Otago, Otago, New Zealand B J Taylor

Correspondence to: Dr E A Mitchell, Department of Paediatrics, University of Auckland, Private Bag 92019, Auckland, New Zealand. 485 postneonatal SIDS cases over three years (1 November 1987 to 31 October 1990) in the study regions. These were compared with 1800 controls who were a random sample of all births, excluding home births (less than $1 \%$ ). For control infants a nominated date and time $S$ Williams, J M D Thompson. was used on which to base interview questions, which ensured a similar age and time of death distribution to that expected for cases. Data were obtained by examination of obstetric records and by interview.

Information was obtained about contacts with general practitioners and hospitals (admitted or attended emergency services) for illness within two weeks of the death/nominated day.

Nine of the symptoms of illness reported by parents were assigned a weighted score based on the BabyCheck system ${ }^{8}$ with appropriate modifications to correspond to our questionnaire. ${ }^{4}$ These symptoms were then categorised into three levels of severity: no or mild illness (score $<8$ points), moderateneeds medical advice (score 8-12); and severe - needs to be seen by a doctor without delay and possibly admitted to hospital (score $>12$ ). In addition those subjects with scores of $20+$ were examined. This defines a group at very high risk of serious illness. ${ }^{8}$

Logistic regression was used to calculate odds ratios adjusted for the following possible confounding variables: (a) selection effects: age of infant, region, season, and time; (b) sociodemographic variables: married, occupation, age mother left school, and age of mother; (c) pregnancy factors: number of previous pregnancies, attendance at antenatal clinic and antenatal education classes; (d) infant factors: sex, ethnicity, birth weight, and gestation; and (e) postnatal factors: admission to neonatal unit, breast feeding at discharge from the obstetric hospital, maternal smoking in the last two weeks, sleeping position, and infant sharing a bed with another person in the last sleep. These variables have been defined previously. ${ }^{47}$

Positive predictive values (PPV) of the BabyCheck score were calculated by the method of Vecchio. ${ }^{9}$ The PPV describes the proportion of infants with a positive screening test who subsequently develop the condition. This was calculated for the age group 8-11 weeks inclusive, as this age group has the highest risk of SIDS. A postneonatal SIDS mortality rate of 3.53/ 1000 live births was used.

The study was approved by ethics committees in each of the participating regions.

† D M O Becroft, E Allen, D Barry, A Roberts, I B Hassall,

\section{Results}

Interviews were completed in 393 SIDS cases $(81.0 \%)$ and 1592 controls (88.4\%). Obstetric records were examined in 465 SIDS cases $(95.9 \%)$ and 1762 controls $(97.9 \%)$.

Increasing severity of illness was associated with an increased risk of SIDS after adjustment 
Table 1 Risk of SIDS associated with severity of illness and with acute medical contacts

\begin{tabular}{|c|c|c|c|c|}
\hline & SIDS, No (\%) & Controls, No (\%) & Univariate $O R(95 \% C I)$ & Multivariate OR $(95 \% \mathrm{CI})$ \\
\hline \multicolumn{5}{|c|}{ Severity of illness based on BabyCheck } \\
\hline Nil or mild & $270(78.0)$ & $1334(88.2)$ & 1.00 & 1.00 \\
\hline Moderate & $54(15.6)$ & $142(9.4)$ & $1.88(1.32$ to 2.67$)$ & $1.42(0.92$ to 2.19$)$ \\
\hline Severe & $22(6.4)$ & $36(2.4)$ & $3.02(1.69$ to 5.38$)$ & $2.36(1.14$ to 4.90$)$ \\
\hline \multicolumn{5}{|c|}{ Acute medical contact — seen by general practitioner } \\
\hline No & $202(54.2)$ & $957(61.4)$ & 1.00 & 1.00 \\
\hline Yes & $171(45.8)$ & $601(38.6)$ & 1.37 (1.09 to 1.72$)$ & $1.09(0.81$ to 1.47$)$ \\
\hline \multicolumn{5}{|c|}{ Acute medical contact-seen at hospital } \\
\hline No & $348(89.7)$ & $1535(96.7)$ & 1.00 & 1.00 \\
\hline Yes & $40(10.3)$ & $53(3.3)$ & $3.43(2.23$ to 5.27$)$ & $1.72(0.96$ to 3.08$)$ \\
\hline
\end{tabular}

$\mathrm{OR}=$ odds ratio $\mathrm{CI}=$ confidence interval.

for potential confounding variables (table 1). Only one SIDS case $(0.3 \%)$ and four controls $(0.3 \%)$ had scores of $20+$.

Significantly more SIDS infants had contact with general practitioners or hospitals because of acute illness in the preceding two weeks compared with control infants (table 1). However, this association was not significant after adjustment for potential confounders, including severity of illness.

We examined the relation between severity of illness and medical contacts. For each category of illness severity, a higher percentage of SIDS infants was seen by the general practitioner within the last two weeks than of control infants: nil or mild illness, $103 / 259(39.7 \%) v$ $477 / 1306$ (36.5\%); moderate, $31 / 50(62.0 \%) v$ $69 / 140$ (49.3\%); severe, $15 / 20$ (75.0\%) v 22/36 $(61.1 \%)$, respectively.

An infant aged 8 to 11 weeks with a severe illness would have approximately 1 in 1300 chance of dying from SIDS in the next seven days. Infants younger or older than 8-11 weeks would be at an even lesser risk.

\section{Discussion}

We have confirmed previous studies which showed that a small number of SIDS infants have symptoms of severe illness ${ }^{1-4}$ and that SIDS infants are more likely to have been seen by a general practitioner or at a hospital. ${ }^{3}$

The belief that recognition of severe illness by the parents and appropriate medical management might prevent some SIDS deaths resulted in the advice to parents in the United Kingdom to seek medical attention promptly if their baby seems unwell. This was incorporated in the Back to Sleep campaign. ${ }^{5}$ However, we found that SIDS infants were taken to a general practitioner more often than control infants for the same severity of illness. Indeed, only $1.3 \%$ of all SIDS cases had symptoms suggestive of severe illness and had not seen a general practitioner.

Recall bias is a potential problem with retrospective studies. Possibly parents of cases may recall and report more trivial symptoms than controls. This might explain the increased risk of SIDS associated with severity of illness.
However, contact with the general practitioner and hospital in the previous two weeks is less likely to be subject to recall bias, and was more frequent in SIDS cases than controls, suggesting that SIDS cases were experiencing more illness than the controls.

It has been argued the BabyCheck score is a useful tool for parents to screen for serious illness. ${ }^{8}$ However, symptoms of illness are poor predictors of SIDS. We calculated that approximately one in 1300 infants with severe illness would subsequently die of SIDS in the next seven days. Nearly all these infants are seen by general practitioners so it is difficult to know how a general practitioner could either predict or prevent the occurrence of SIDS in these circumstances.

We conclude that lack of appropriate medical contact for illness cannot be implicated as a contributing cause of SIDS.

This study was funded by the Health Research Council of New Zealand (HRCNZ) and the Hawke's Bay Medical Research Foundation. We sincerely thank the parents and families who participated in this study. We also thank the research interviewers and pathologists in the study regions. Mrs C Everard coordinated the study and $\mathrm{Mr}$ P Schulter assisted with the analysis. $\mathrm{Mr}$ Stewart, Mr Thompson, and Mrs Everard were supported by the HRCNZ.

1 Stanton AN, Downham MAPS, Oakley JR, Emery JL, Knowelden J. Terminal symptoms in children dying suddenly and unexpectedly at home. Preliminary report of the DHSS multicentre study of postneonatal mortality. BMF 1978;ii: 1249-51.

2 Hoffman HJ, Damus K, Hillman L, Krongrad E. Risk Hoffman HJ, Damus K, Hillman L, Krongrad E. Risk
factors for SIDS. Results of the National Institute of Child health and Human Development SIDS cooperative epidehealth and Human Development SIDS cooperative epide-
miological study. Ann NY Acad Sci 1988;533:13-30.

3 Gilbert RE, Fleming PJ, Azaz Y, Rudd PT. Signs of illness preceding sudden unexpected death in infants. BMF 1990; 300:1237-9. [Correction in BMF 1990;300:1378.]

4 Taylor BJ, Williams SM, Mitchell EA, Ford RPK. Symptoms, sweating and reactivity of infants who die of SIDS compared with community controls. F Paediatr Child Health 1996;32:316-22.

5 Department of Health. Report of the Chief Medical Officer's Expert Group on the sleeping position of infants and cot death. London: HMSO, 1993.

6 Mitchell EA, Scragg R, Stewart AW, et al. Results from the first year of the New Zealand cot death study. NZ Med $\mathcal{F}$ 1991;104:71-6.

7 Mitchell EA, Taylor BJ, Ford RPK, et al. Four modifiable and other major risk factors for cot death: the New Zealand and other major risk factors for cot death: the New Zeal

Study. F Paediatr Child Health 1992;28(suppl 1):S3-8.
8 Morley CJ, Thornton AJ, Cole TJ, Hewson PH, Fowler Morley CJ, Thornton AJ, Cole TJ, Hewson PH, Fowler
MA. BabyCheck: a scoring system to grade the severity of acute systemic illness in babies under 6 months. Arch Dis Child 1991:66:100-6.

9 Vecchio TJ. Predictive value of a single diagnostic test in unselected populations. N Engl f Med 1966;274:1171-3. 